\title{
SCOPAFUNGIN, A CRYSTALLINE ENDOMYCIN COMPONENT
}

\author{
M. E. Bergy and H. HoEKSEMA \\ Infectious Diseases Research, The Upjohn Company, \\ Kalamazoo, Michigan 49001, U.S.A.
}

(Received for publication September 8, 1971)

\begin{abstract}
Scopafungin is the major component of the non-polyenic endomycin complex which was extracted from Streptomyces hygroscopicus var. enhygrus var. nova and purified by partition column chromatography or silica gel column chromatography followed by crystallization. It is a white crystalline compound which contains carbon $(60.95 \%)$, hydrogen $(9.00 \%)$, nitrogen $(4.01 \%)$ and oxygen $(26.46 \%)$ and melts at $119.3^{\circ} \mathrm{C}$. In methanol, $0.1 \mathrm{~N} \mathrm{HCl}$ in methanol, and $0.1 \mathrm{~N} \mathrm{KOH}$ in methanol, it exhibits maximum UV absorption at $231 \mathrm{~nm}$ and is dextrorotatory in dimethylformamide, $[\alpha]_{\mathrm{D}}^{25}+20$. Titration in glacial acetic acid indicates an equivalent weight of 1268. Scopafungin is soluble in lower alcohols, glacial acetic acid, acetone-water $(3: 2)$ and water-saturated 1-butanol, but is insoluble in water, acetone, ethyl acetate, methyl ethyl ketone, methylene chloride, chloroform, butanol or ether.
\end{abstract}

The production and characteristics of endomycin were initially reported by Gottuieb $e$ t $a l^{1,2)}$. VINING and $\mathrm{TABER}^{3)}$ later focused their attention on two polyenes present in the endomycin complex. They separated them by paper chromatography and countercurrent distribution and designated them endomycin $\mathrm{A}$, a tetraene, and endomycin B, a hexaene. The non-polyenic endomycin portion, however, remained unresolved.

Subsequent advances in purification techniques, particularly in thin-layer chromatography and column chromatography have prompted us to investigate the homogeneity of the non-polyenic endomycin. Thin-layer chromatography on silica gel revealed the first evidence that it was a complex and subsequent column chromatography substantiated the presence of one major and several minor active components mixed with inactive impurities. The major component was separated and successfully purified to a crystalline state. It is named scopafungin although it has been referred to as either enhygrofungin or U-29,479 in other Upjohn communications. Its purifcation and characterization is the subject of this paper. The endomycin complex used in this investigation was produced by Streptomyces hygroscopicus var. enhygrus and it is identical to the endomycin produced by the original organism, Streptomyces endus. The fermentation and biological properties of scopafungin are reported by JOHNSON and DieTz $Z^{4}$.

\section{Isolation and Purification}

Scopafungin was extracted from the mycelium with 1-butanol and precipitated with petroleum ether. The precipitate was dissolved in ethanol and water and concentrated to dryness. The scopafungin was purified by partition chromatography 
with a solvent system composed of methyl ethyl ketone-ethyl acetate-water, and crystallized from an aqueous extract of the appropriate column fractions. It was recrystallized from acetone and water.

Scopafungin was also purified by silica gel column chromatography with the solvent system methyl ethyl ketone-acetone-water and crystallized from acetone-water.

\section{Characterization}

Scopafungin is a white crystalline compound which is soluble $(>10 \mathrm{mg} / \mathrm{ml})$ in methanol, ethanol, $n$-propanol, glacial acetic acid, acetone-water $(3: 2)$ and watersaturated 1-butanol but insoluble $(<5 \mathrm{mg} / \mathrm{ml})$ in water, acetone, ethyl acetate, methyl ethyl ketone, methylene chloride, chloroform, 1-butanol and ether.

Electrometric titration in glacial acetic acid with perchloric acid afforded an equivalent weight of 1268 . The molecular weight was not determined. Scopafungin does not give a satisfactory mass spectrum. Elemental analysis of scopafungin revealed the following composition:

Found: $\mathrm{C} 60.95$ ( $\mathrm{WO}_{3}$ catalyst), $\mathrm{H} 9.00, \mathrm{~N} 4.01, \mathrm{O} 26.46$ (direct).

Scopafungin shows the following ultraviolet absorptions:

Methanol: Infl. @ $227 \mathrm{~nm}, \mathrm{a}=25.77$.

Max.@231 nm, a=27.22.

S1. Infl. @ $240 \mathrm{~nm}, \mathrm{a}=17.74$.

$0.1 \mathrm{~N} \mathrm{HCl}$ in methanol: Infl.@226 nm, a=25.96.

Max.@231nm, a=27.34.

Sl. Infl.@ $240 \mathrm{~nm}, \mathrm{a}=17.97$.

$0.1 \mathrm{~N} \mathrm{KOH}$ in methanol: Inf. @ $227 \mathrm{~nm}, \mathrm{a}=25.70$.

S1. Infl.@240 nm, $a=18.02$.

The ultraviolet absorption spectrum in methanol is shown in Fig. 1, the infrared absorption spectrum in Nujol mull in Fig. 2, the proton magnetic resonance spectrum in deuterated dimethylformamide in Fig. 3 (chemical shifts expressed from tetramethylsilane), and the paper chromatographic spectrum in Fig. 4. Scopafungin melts at $119.3^{\circ} \mathrm{C}$ and has a specific rotation of $[\alpha]_{\mathrm{D}}^{25}+20$ (c) 0.46 , dimethylformamide).

\section{Experimental}

Isolation from Fermentation Broth

Whole broth $(2,800 \mathrm{ml} ; 1925 \mathrm{mcg} / \mathrm{ml}$ scopafungin equivalents) was adjusted to $\mathrm{pH}$ $4.5(\mathrm{HCl})$ and filtered with diatomaceous earth filter aid $(2 \%, \mathrm{w} / \mathrm{v})$. The filtrate $(2,800 \mathrm{ml} ; 25 \mathrm{mcg} / \mathrm{ml}$ scopafungin equivalents $)$ was discarded but the filter cake was

Fig. 1. Ultraviolet absorption spectrum of scopafungin in methanol.

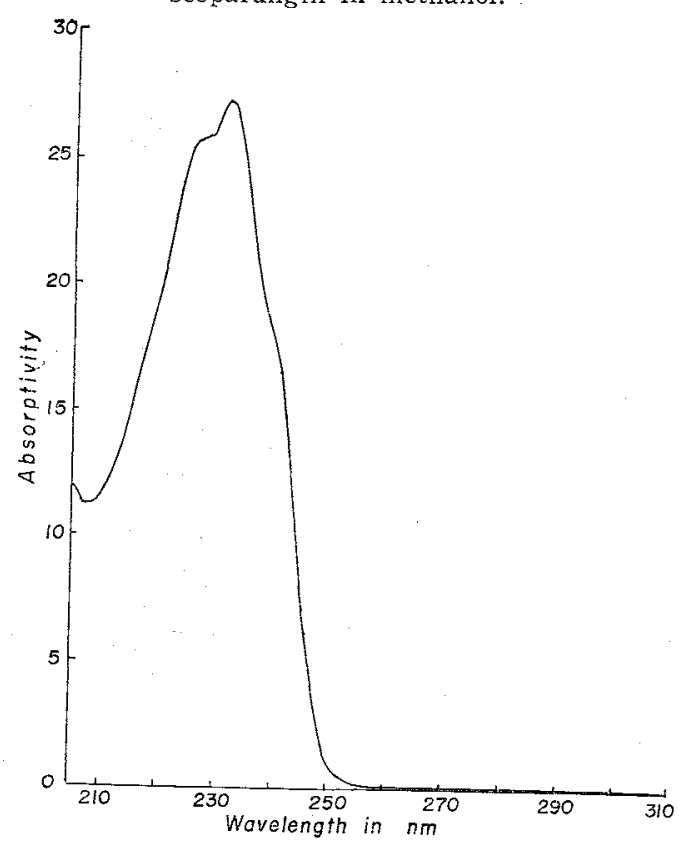


Fig. 2. Infrared absorption spectrum of scopafungin as a Nujol mull.

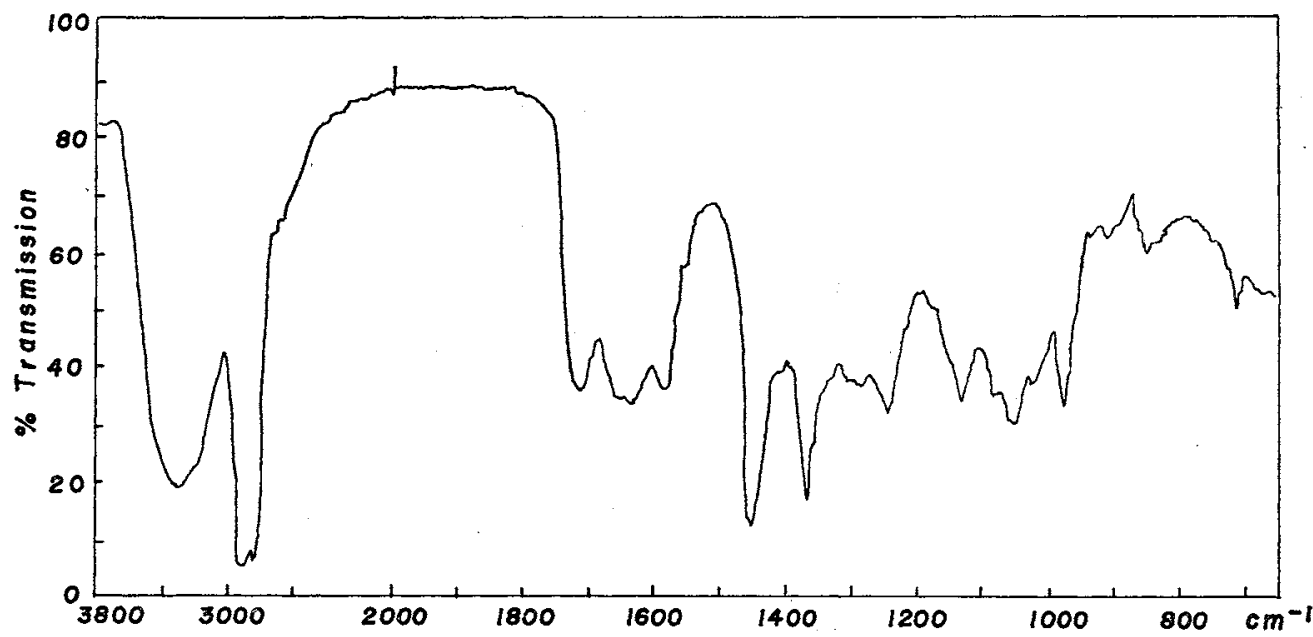

Fig. 3. Proton magnetic resonance spectrum of scopafungin in deuterated dimethylformamide.

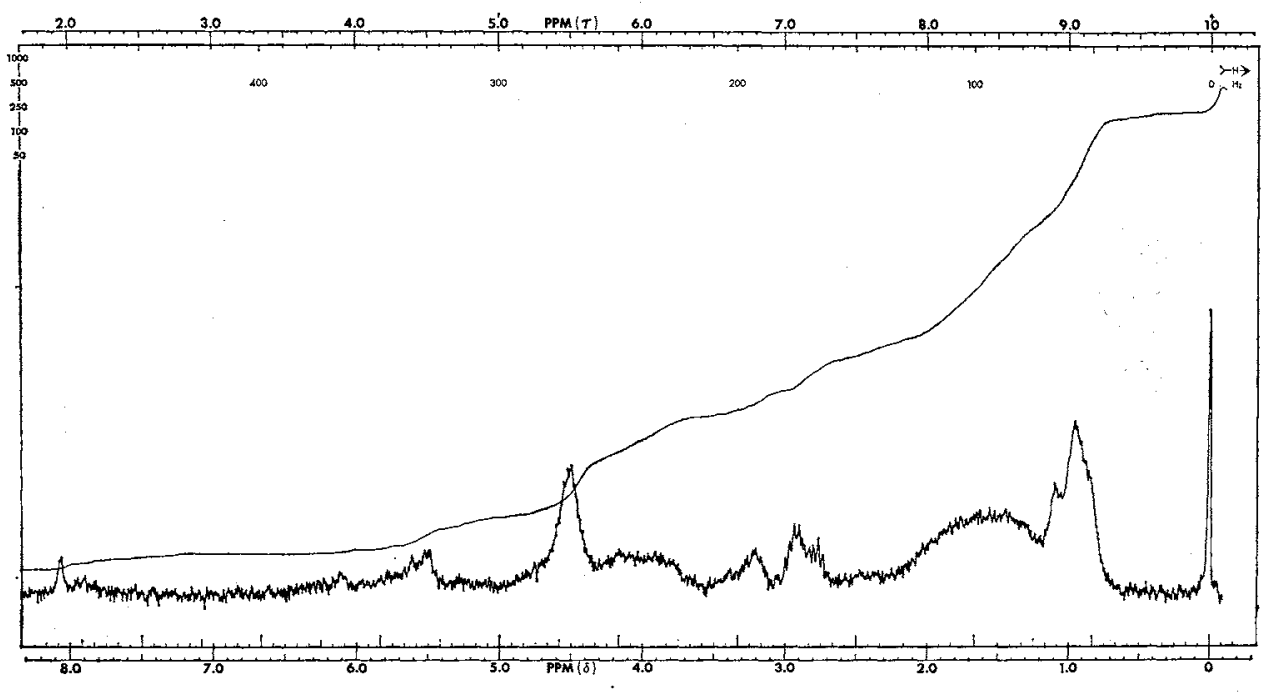

extracted three times at $50^{\circ} \mathrm{C}$ with $700 \mathrm{ml}$ portions of water-saturated 1-butanol and the phases were separated. The combined 1 -butanol extracts $(1,950 \mathrm{ml})$ were mixed with three volumes $(6,000 \mathrm{ml})$ of Skellysolve B. The resulting precipitate was dissolved in 370 $\mathrm{ml}$ of ethanol-water $(4: 1)$ and the solution was evaporated to dryness in vacuo (yield, $1.73 \mathrm{~g} .420 \mathrm{mcg} / \mathrm{mg}$ scopafungin equivalents). This preparation contained a complex of polyenic and non-polyenic endomycins-scopafungin was the major non-polyenic component.

Partition Chromatography and Crystallization

Scopafungin was separated from the endomycin complex and purified by partition column chromatography and subsequent crystallization.

Diatomaceous earth $(3,000 \mathrm{~g})$ was mixed with approximately 35 liters of upper phase (solvent system: methyl ethyl ketone-ethyl acetate-water, $100: 50: 15$ ) and exactly 1.2 liters of lower phase solvent. This mixture was poured into a glass chromatography column (10 cm diameter) and the earth was packed to a constant height $(137 \mathrm{~cm})$ with down-flowing upper phase solvent. The solvent level was drained to approximately $2 \mathrm{~cm}$ above the packed column bed. 
Impure scopafungin $(75 \mathrm{~g}$, potency $250 \mathrm{mcg} / \mathrm{mg}$ scopafungin equivalents) was dissolved in $120 \mathrm{ml}$ of lower phase solvent and mixed with $240 \mathrm{~g}$ of diatomaceous earth and enough upper phase solvent to make the mixture fluid. This mixture was poured onto the prepared column bed and the solvent level was drained to the new bed level. Fresh upper phase solvent was added and the column was developed at a flow rate of 16 liters per hour. Four-liter fractions were collected after the introduction of the fresh upper phase solvent.

Analyses of the column fractions by thinlayer chromatography proved that fractions 9 through 23 contained the major proportion of purified scopafungin. Therefore, these fractions were combined (volume, 60 liters) and mixed with a half-volume quantity (30 liters) of petroleum ether. The solvent phases were separated and the top phase was extracted with water $(500 \mathrm{ml})$.

The solvent phases were again separated and the top phase was discarded but the two aqueous phases were combined (volume, $4.300 \mathrm{ml}$ ), adjusted to $\mathrm{pH} 3.8(\mathrm{HCl}$ ), mixed with water $(2,150 \mathrm{ml})$, clarified by filtration, cooled and held at $5^{\circ} \mathrm{C}$ until crystallization was complete. The crystalline scopafungin was removed by filtration, washed with water, and dried in vacuum at room temperature to a constant weight $(10.5 \mathrm{~g})$.

Crystalline scopafungin $(8.64 \mathrm{~g})$, so derived, was dissolved in $165 \mathrm{ml}$ of acetone-water $(3: 2)$ and the solution was adjusted to $\mathrm{pH} 4.0(\mathrm{HCl})$ and filtered. The clarified solution was mixed with $1,500 \mathrm{ml}$ of water and stirred until crystallization started (10 minutes). The crystallizing mixture was stored overnight at $2^{\circ} \mathrm{C}$. The recrystallized scopafungin was removed by filtration, washed with water $(25 \mathrm{ml})$ and dried in vacuum at room temperature to a constant weight $(8.3 \mathrm{~g})$.

Silica Gel Chromatography and Crystallization

Scopafungin was separated from the endomycin complex and purified also by silica gel column chromatography and crystallization.

Silica gel ( 7734 , Merck, A.G., Darmstadt, $5 \mathrm{~kg}$ ) was mixed with petroleum ether and poured into a $10 \mathrm{~cm}$ diameter glass chromatography column and packed to a constant height $(122 \mathrm{~cm})$ with flowing petroleum ether.

Impure scopafungin ( $25 \mathrm{~g}, 650 \mathrm{mcg} / \mathrm{mg}$ scopafungin equivalents) was dissolved in methanol $(100 \mathrm{ml})$ and mixed with silica gel $(\sharp 7734,200 \mathrm{~g})$. The methanol was removed by evaporation in circulating air. The dried mixture was poured into a layer of petroleum ether remaining on top of the column bed. The level of petroleum ether was drained to the level of the load and fresh solvent composed of methyl ethyl ketone-acetone-water $(150: 50: 28)$ was introduced and used to develop the column at a flow rate of 12 liters per hour. Fractions (4 liters) were collected and analyzed for scopafungin content by thinlayer chromatography as described in the thin-layer chromatography section.

Fractions 16 through 25 contained the purified scopafungin and they were combined and concentrated in vacuum to an aqueous solution which was freeze dried $(12.5 \mathrm{~g})$. A portion $(50 \mathrm{mg})$ of this dried preparation was dissolved in $8 \mathrm{ml}$ of acetone-water $(3: 1)$, mixed with $58 \mathrm{ml}$ of water, and refrigerated until crystallization was complete. The crystalline scopafungin was removed by filtration, washed with water, and dried in vacuum at room temperature to a constant weight $(39 \mathrm{mg}, 930 \mathrm{mcg} / \mathrm{mg}$ potency).

Thin-Layer Chromatography 
Scopafungin was analyzed by thin-layer chromatography on glass plates which were prepared with silica gel $\mathrm{HF}_{254}$ (E. Merck, A.G., Darmstadt, Germany) suspended in a solution of buffer salts composed of equal volumes of $0.2 \mathrm{M} \mathrm{Na} \mathrm{Na}_{2} \mathrm{HPO}_{4}$ and $0.2 \mathrm{M} \mathrm{KH}_{2} \mathrm{PO}_{4}$. The plates were air-dried, then activated at $130^{\circ} \mathrm{C}$ for 2 hours prior to their use. To analyze column fractions, $2 \mathrm{ml}$ portions of fractions were evaporated to dryness with a stream of nitrogen and the residue was dissolved in $0.1 \mathrm{ml}$ of methanol. Ten mcl of this concentrate was applied to the plate and developed with methyl ethyl ketone-acetonewater $(150: 50: 34)$. To analyze dried preparations, loads equivalent to $25 \sim 50 \mathrm{mcg}$ of scopafungin chromatographed well. After development, the plates were dried in the air, then sprayed with a freshly prepared mixture of anisaldehyde - $95 \%$ ethanol-concentrated sulfuric acid-glacial acetic acid $[0.5: 9.0: 0.5: 0.1(\mathrm{ml})]$ and heated to $90 \sim 100^{\circ} \mathrm{C}$ for $5 \sim 10$ minutes. Scopafungin appeared as a dark blue spot, $\mathrm{Rf}=$ approximately 0.23 .

Paper Chromatography

Scopafungin (25 mcg) was applied to Whatman $\# 1$ paper strips and developed by descending flow and bioautographed on Saccharomyces cerevisiae seeded trays.

\section{Acknowledgements}

The authors wish to express their appreciation to various members of the Upjohn Company who contributed to this work. In particular, we wish to thank Mr. W. H. De VRTES for his adaptation of the extraction procedures to large scale fermentations and members of the Physical and Analytical Chemistry Department for spectral and analytical data. The technical assistance of Mr. J. A. SHILEY and Mr. D. R. WAIr is greatly appreciated.

\section{References}

1) Gotmlieb, D.; P. K. Bhatpacharyya, H. E. Carter \& H. W. Anderson: Endomycin, a new antibiotic. Phytopathology $41: 393 \sim 400,1951$

2) Gottliteb, D. \& H.E. Carter : Endomycin and process for its production. U. S. Patent 2,746,902, May 22, 1956

3) Vining, L. C. \& W. A. TABer: Separation of endomycins A and B, and their identification as members of the polyene groups of antifungal antibiotics. Can. J. Chem. 35: 1461 1466, 1957

4) Johnson, L. E. \& A. Dietz: Scopafungin, a crystalline antibiotic produced by Streptomyces hygroscopicus var. enhygrus var. nova. J. Appl. Microbiol. $22: 303 \sim 308,1971$ 